\title{
Gender Effects in a General Physics Laboratory Assessment
}

\section{Dr. Robert A Ross, University of Detroit Mercy}

Robert A. Ross is a Professor of Physics in the Department of Chemistry \& Biochemistry at the University of Detroit Mercy. His research interests include semiconductor devices and physics pedagogy. Ross received his B.S. and Ph.D. degrees in Physics from Wayne State University in Detroit.

\section{Dr. E. Prasad Venugopal, University of Detroit Mercy}

E. Prasad Venugopal is an Associate Professor of Physics in the Department of Chemistry \& Biochemistry at the University of Detroit Mercy. His research interests include physics education research and science and technology studies. Venugopal received his Ph.D. from the University of Massachusetts at Amherst, MA.

\section{Ms. Meghann Norah Murray}

Meghann Murray has a position and conducts research in the Department of Chemistry \& Biochemistry at University of Detroit Mercy. She received her B.S. and M.S. degrees in chemistry from UDM and is certified to teach high school chemistry and physics. She has taught in programs such as the Detroit Area Pre-college and Engineering program. She has been a judge and mentor with the Science and Engineering Fair of Metropolitan Detroit, FIRST Lego League, and FRC Robotics. She is currently the Chair of the Younger Chemists Committee and Treasurer of the Detroit Local Section of the American Chemical Society.

\section{Prof. Gary P. Hillebrand, University of Detroit Mercy}

Lecturer in Physics at the University of Detroit Mercy since 2008, following 30 years in automotive product development at Ford and GM.

Dr. Matthew Gonderinger, University of Detroit Mercy, Wayne State University 


\section{Gender Effects in a General Physics Laboratory Assessment}

\section{Introduction}

Twenty years ago the second-semester general physics laboratory courses at the University of Detroit Mercy adopted an active-learning curriculum based on the work of both Arnold Arons ${ }^{1}$ and Lillian McDermott's group at the University of Washington. We use adaptations of Physics by Inquiry ${ }^{2}$ and Tutorials in Introductory Physics ${ }^{3}$ to implement a batteries and bulbs curriculum. ${ }^{4}$ This curriculum is research-based ${ }^{5,6}$ and we believe it gives all students an opportunity to be successful in understanding important concepts in direct current circuits. Some recent work has shown that in addition to bulbs, electric fans can be used to teach about circuits. The fans allow students who are visually impaired to use a tactile response to sense how much current is flowing through a fan motor. ${ }^{7}$

The College of Engineering \& Science at the University of Detroit offers two physics sequences, one algebra-based and one calculus-based. The calculus-based general physics sequence is a requirement for all engineers and for chemistry majors. As general physics is a prerequisite for the engineering class in statics, most engineers take the first-semester of physics in the winter of their freshman year and subsequently take the second semester of physics in the fall of their sophomore year. The second-semester of physics is a prerequisite for physical chemistry, required of chemistry majors, and an upper-level modern physics course required for electrical engineers. The students enrolled in the algebra based courses are biology or biochemistry majors. Since physics is not a prerequisite for any courses in the biology and biochemistry curriculum, a large fraction of these majors take general physics in their junior or senior year. Regardless of major, all students taking the introductory sequence are enrolled in the same inquiry-based second-semester general physics laboratory. Consequently, assessing the impact of the shared laboratory curriculum takes on added importance to determine if students are learning what we are teaching. ${ }^{8}$

\section{Gender \& Pedagogical Issues in Physics Assessment Tests}

The impact of gender on undergraduate enrollments and pedagogy have bedeviled the physics educational community for many decades. ${ }^{9,10}$ Among all fields of science and engineering, physics continues to have among the lowest representation of females at the undergraduate level. The situation deteriorates at higher levels on the educational and professional ladder. ${ }^{11}$ The gender gap in the participation of females is exacerbated by research showing that female students consistently perform worse than males in introductory physics courses. ${ }^{12}$ This combination of under-representation and under-performance is the consequence of multiple inter-related factors that defy easy explanation or solution. At the broadest level, a significant body of research has critiqued the "masculine nature of science and how that has affected women's participation in science." 13 The coupling of disparities in preparation and differing attitudes about math and physics at the high school level, may partially account for female underperformance in college-level physics courses. ${ }^{14,15}$ Within the college classroom, pedagogical 
practices involving curriculum, instruction and assessment have been implicated in creating or sustaining gender disparities in student learning. In particular, changing the contexts of physics problems and questions to be more gender-inclusive and concrete (rather than abstract) ${ }^{16}$, or using interactive-engagement (as opposed to traditional) methods of teaching ${ }^{17,18}$ have been shown, though inconsistently, to enhance the learning gains of women and under-represented minorities.

Recently, greater attention has been paid to the issue of gender bias in standardized physics assessment instruments. ${ }^{19,20,21}$ The two most commonly used mechanics concept tests, the FCI and the FMCE, have shown that male pre-test and post-test scores are consistently higher than those of females taking the test, though the underlying reasons for this are unclear and defy easy explanation. $^{22}$ There have been fewer studies investigating the existence of the gender gap in electricity and magnetism assessment tests. ${ }^{23,24}$ This "gender gap" is of concern however, since the effectiveness of curricular or pedagogical reforms in introductory physics are judged using the same instruments. Whether these effects are artifacts of the tests or the underlying instruction remains an open question. However, a review of the literature shows the introductory mechanics physics lecture course to be the predominant context within which these tests are administered. The use of these instruments to assess student learning in laboratory courses is not as common. In this paper, we focus on one assessment that is well-suited to the inquiry-based secondsemester physics laboratory curriculum. The main goal of our work is to investigate the existence of a gender gap as evidenced by student performance on the test.

\section{Statistical Analysis of DIRECT}

One of the assessment instruments we have been using for our second-semester general physics laboratory courses is the Determining and Interpreting Resistive Electric Circuit Concepts Test (DIRECT). ${ }^{25}$ DIRECT is a set of 29 multiple choice questions on direct-current circuits, each with 5 possible responses. We obtained the latest version of DIRECT from the authors, which we understand to be essentially the same as previous versions of the test. Beginning in the winter of 2004 we have administered DIRECT to 700 students (394 females and 306 males) enrolled in the algebra-based sequence and 395 students (109 females and 286 males) enrolled in the calculusbased sequence. We have previously reported on results from analyzing the performance of our students relative to a national sample provided by the authors of DIRECT. ${ }^{26,27}$ In this work, we further analyze the statistics of the test by investigating to what extent the students' level of preparation (algebra-based versus calculus-based) and gender (make versus female) affected the performance of students in the second-semester laboratory.

In Figure 1 on the following page, we show how Detroit Mercy students compare with those from the national sample provided by the authors of reference 25 . The graph shows the percentage of students in a respective group (males, females, algebra-based, and calculus-based) that answered the particular question correctly minus the percentage of correct responses from the national sample. In Table I, below, we show the average deviation for each of the four groups and also the number of questions in which the deviation was positive. When the deviation is positive Detroit Mercy students, on average, scored higher than those from the national sample. 


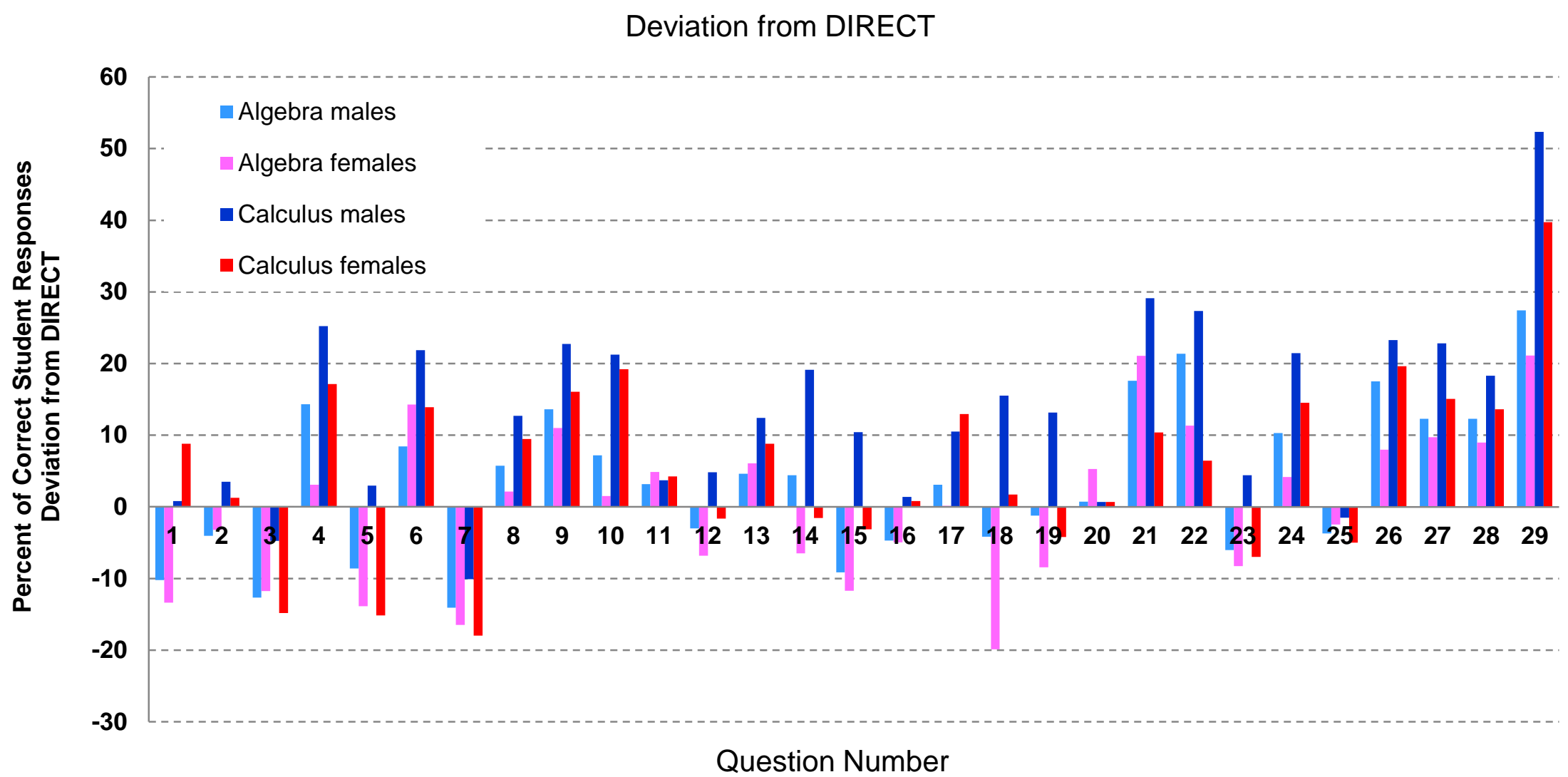

Fig. 1

Average percentage of correct student responses for males and females in algebra and calculus based courses minus the average percentage of correct student responses in the national sample from DIRECT (reference 25). 


\begin{tabular}{|l|c|c|}
\cline { 2 - 3 } \multicolumn{1}{c|}{} & $\begin{array}{c}\text { Average percent deviation } \\
\text { from DIRECT }\end{array}$ & $\begin{array}{c}\text { Number of questions where } \\
\text { deviation is positive }\end{array}$ \\
\hline Algebra Female & 0.2 & 16 \\
\hline Algebra Male & 3.5 & 17 \\
\hline Calculus Female & 5.7 & 20 \\
\hline Calculus Male & 13.2 & 26 \\
\hline
\end{tabular}

Table I

Average percent deviation of the four groups of students from the national sample, and the number of questions (out of the total of 29) where the deviation was positive.

Information about the distribution of scores is relevant in determining if the differences are real or the result of chance. To investigate this we generated functions that show the percentage of students, in a particular course, that attained a given score on DIRECT. The results are shown below in Figures 2 and 3; one for the algebra cohort and one for the calculus cohort.

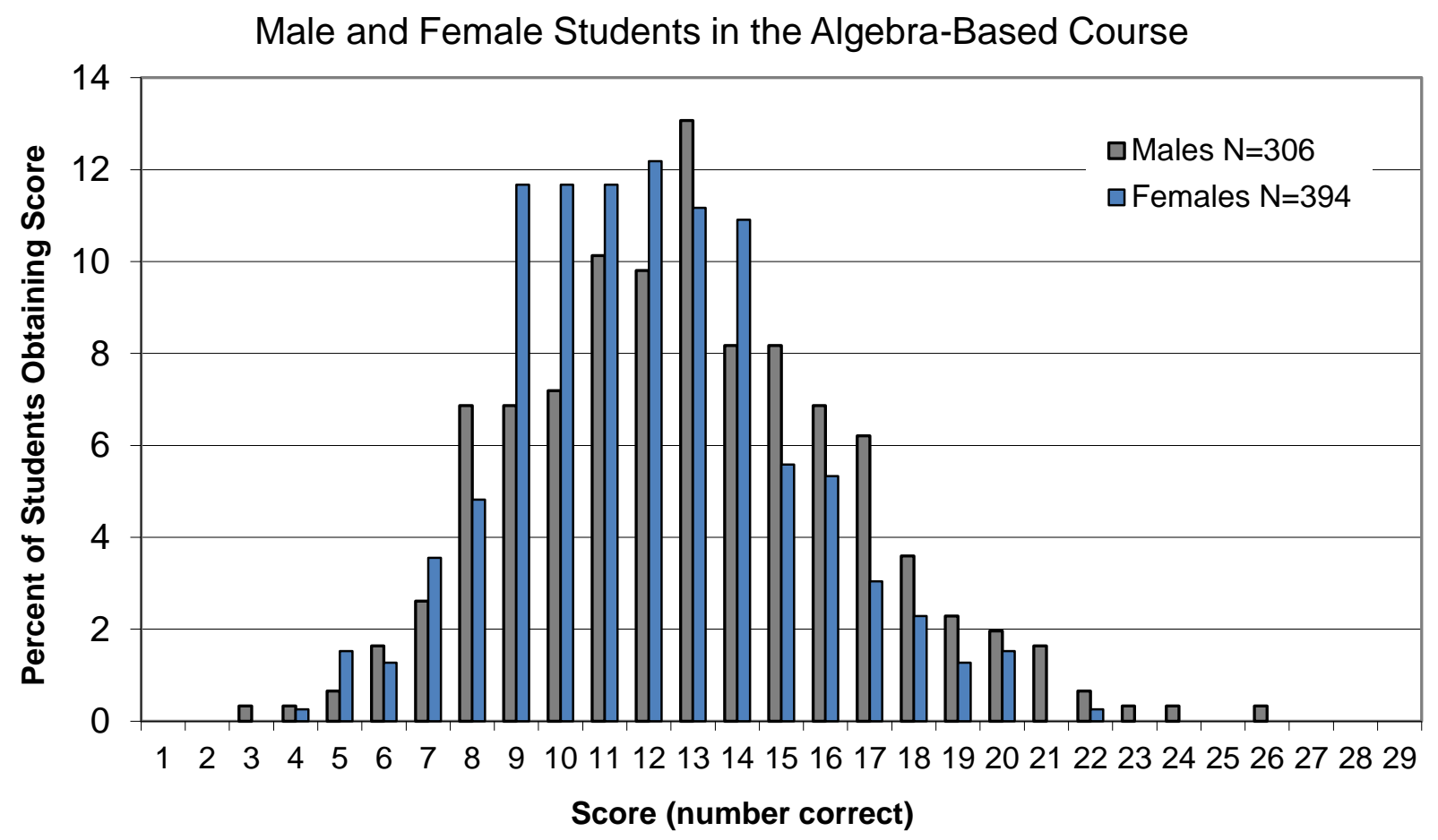

Fig. 2

Percentage of students in the algebra-based course with the given score. 


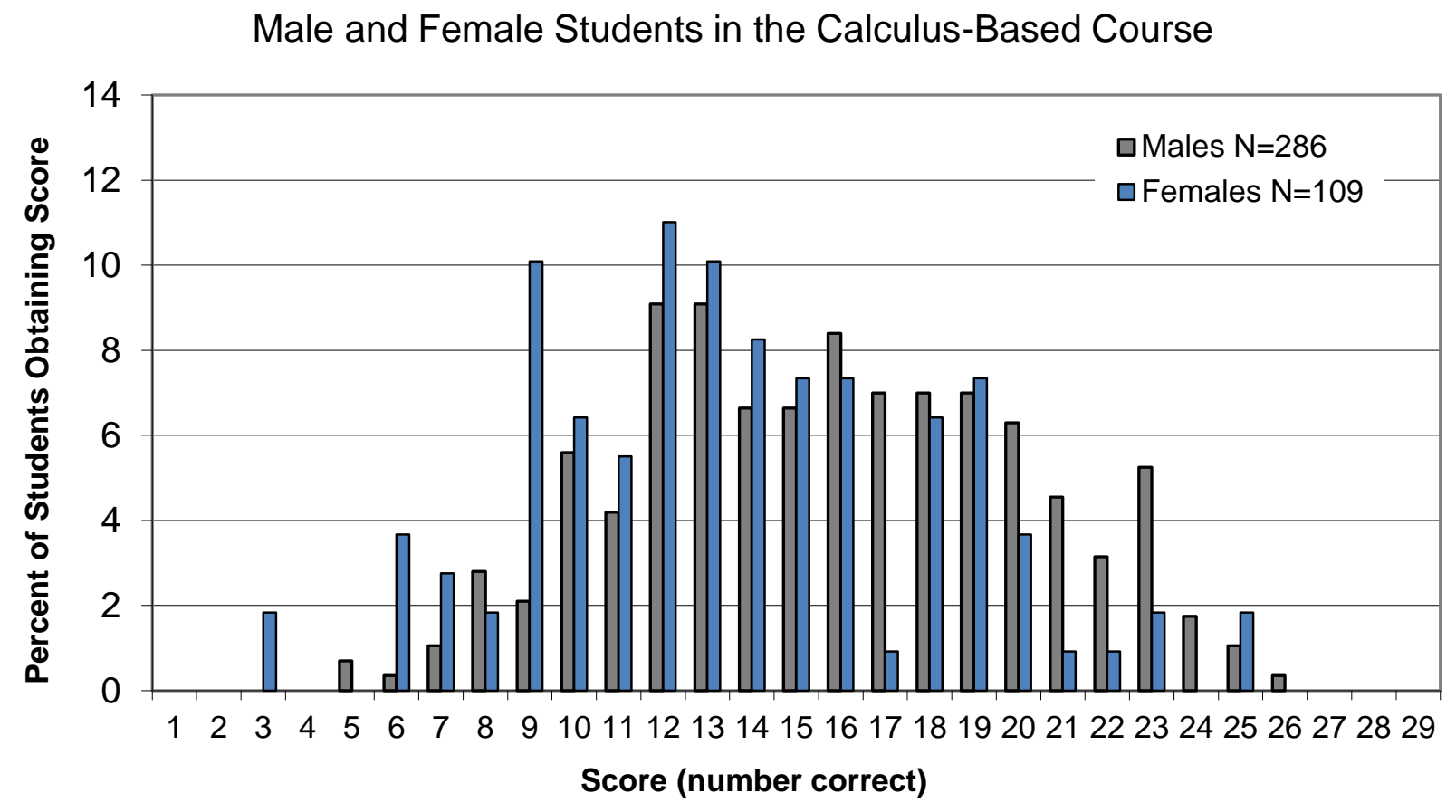

Fig. 3

Percentage of students in the calculus-based course with the given score.

In Figure 4 we plot the cumulative distribution functions of the scores for each cohort of students. The cumulative distribution function (CDF) is the percentage of students (in a cohort) that score less than or equal to the score on the horizontal axis. If the scores are distributed in a normal or Gaussian fashion they can be represented by $\frac{1}{\sqrt{2 \pi \sigma^{2}}} e^{-\frac{(x-\mu)^{2}}{2 \sigma^{2}}}$ where $x$ is the score, $\mu$ is the mean and $\sigma$ the standard deviation, $\sigma^{2}$ is the variance. The CDF for the normal distribution is the integral of the distribution and is given by $\frac{1}{2}\left(1+\operatorname{erf}\left(\frac{(x-\mu)}{\sqrt{2} \sigma}\right)\right)$ where $\operatorname{erf}(x)$ is the error function given by $\frac{2}{\sqrt{\pi}} \int_{0}^{x} e^{-t^{2}} d t$ and is a standard tabulated function. 


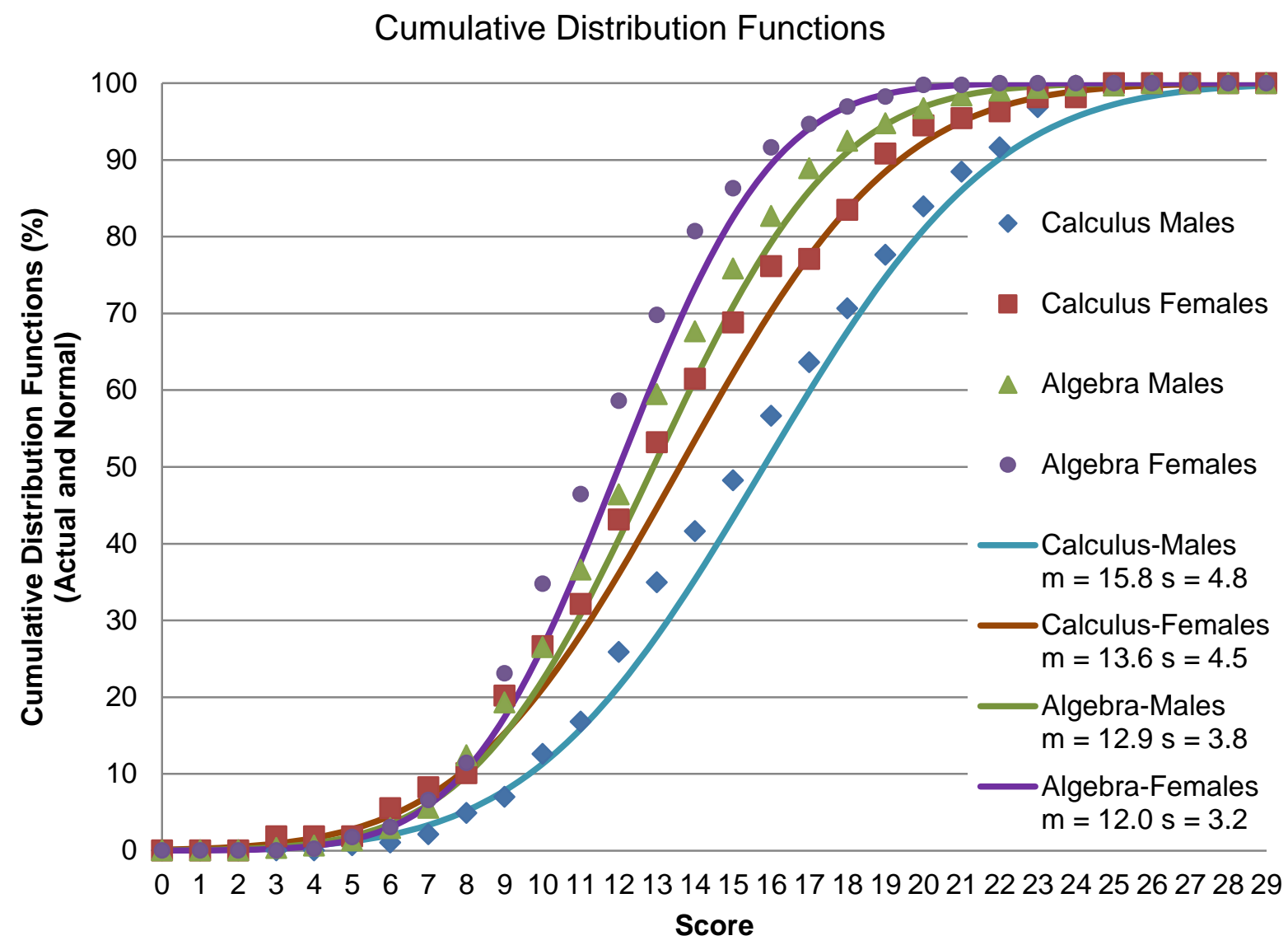

Fig. 4

Actual cumulative distribution functions for male and female students in algebra and calculusbased courses (symbols) along with calculated CDF's with the given means and standard deviations (solid lines).

We tested the CDFs to determine how close each one is to a normal distribution. The results are shown in Figure 5. Here we show the actual CDFs versus the normal CDFs (calculated from the error function) with the given means and standard deviations shown on the plots. If the actual CDF is truly normal, then the plot would be a straight line going through the origin. It is readily apparent that the fit to a normal distribution is excellent. 

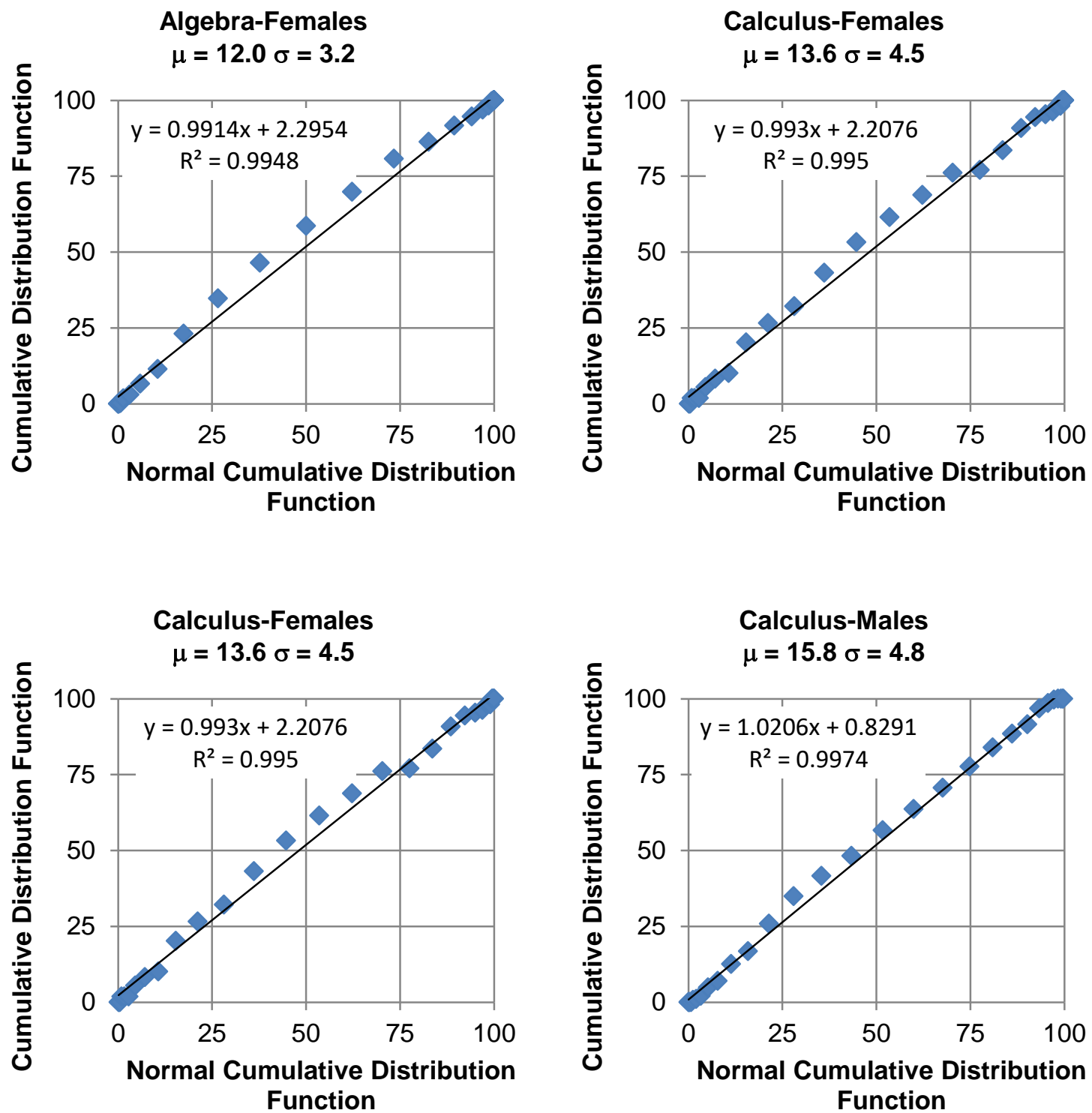

Fig. 5

Actual cumulative distribution functions for male and female students in algebra and calculusbased courses (blue squares) versus calculated normal cumulative distribution functions with the given mean and standard deviations (solid lines). 
The DIRECT authors show the results for male and female university students. They report the mean and standard deviation for female and male students to be $12 \pm 3.7$ and $16 \pm 5.0$, respectively. They noted that there "were no significant differences between calculus-based and algebra-based university students." Since the student score distributions are normal, we performed single tail $t$-tests of significance for both male and female students in the algebra and calculus based courses: comparing males and females in the algebra class $\left(p=1.2 \times 10^{-4}\right)$, males and females in the calculus class $\left(p=6.7 \times 10^{-6}\right)$, males in the algebra and calculus classes $(p=$ $\left.2.1 \times 10^{-16}\right)$, and females in the algebra and calculus classes $\left(p=1.7 \times 10^{-5}\right)$. In contrast with the results from DIRECT, we find a difference between students in the algebra based and calculus based courses that we believe is statistically significant. The variance in the scores for the female students in the algebra based course is half that of the female students in the calculus course. Overall we note that the variance is much smaller for the students in the algebra based course.

One reliability measure of an assessment is the Kuder-Richardson Formula 20 (KR-20) coefficient. ${ }^{28}$ For a test with $K$ items (here $K=29$ ) the reliability coefficient, $r$, is given by $r=\frac{K}{K-1}\left[1-\frac{\sum_{i=1}^{K} u_{i} w_{i}}{\sigma^{2}}\right]$ where $u_{\mathrm{i}}$ is proportion of correct responses for the $i^{\text {th }}$ question and $w_{\mathrm{i}}$ is the proportion of incorrect responses so $u_{\mathrm{i}}+w_{\mathrm{i}}=1$ and $\sigma^{2}$ is the variance-the square of the standard deviation. In Table II we show the mean, variance, standard deviation, median, and sum of the product of correct and incorrect responses for the male and female students in the algebra and calculus-based courses. Note that if students chose all the answers at random, the sum would be 4.64. If all students responded either correctly or incorrectly the sum would be zero. The greatest value of 7.25 occurs if half the population is correct. The results in Table II show interesting similarities and differences with the results given in reference 9.

In Table III we show the results for the KR-20 reliability coefficient. Generally one looks for a coefficient in excess of 0.70 . Here we note that for the algebra-based courses the coefficient is significantly lower. This is due to the smaller variance of scores in the algebra based classes.

\begin{tabular}{|l|c|c|c|c|c|c|}
\cline { 2 - 6 } \multicolumn{1}{c|}{} & $\mathrm{N}$ & mean & variance & std. dev. & median & $\sum_{i=1}^{i=29} u_{i} w_{i}$ \\
\hline Algebra Female & 394 & 12.0 & 10.0 & 3.2 & 12 & 5.46 \\
\hline Algebra Male & 306 & 12.9 & 14.3 & 3.8 & 13 & 5.57 \\
\hline Algebra & 700 & 12.4 & 12.1 & 3.5 & 12 & 5.54 \\
\hline Calculus Female & 109 & 13.6 & 20.3 & 4.5 & 13 & 5.57 \\
\hline Calculus Male & 286 & 15.8 & 19.6 & 4.4 & 16 & 5.33 \\
\hline Calculus & 395 & 15.2 & 20.8 & 4.6 & 15 & 5.46 \\
\hline
\end{tabular}

Table II

The number of students along with the mean, variance, standard deviation, median, and sum of the product of correct $\left(u_{\mathrm{i}}\right)$ and incorrect $\left(w_{\mathrm{i}}\right)$ responses for students given the DIRECT test. 


\begin{tabular}{|l|c|}
\cline { 2 - 2 } \multicolumn{1}{c|}{} & $r$ \\
\hline Algebra Female & 0.47 \\
\hline Algebra Male & 0.63 \\
\hline Calculus Female & 0.75 \\
\hline Calculus Male & 0.75 \\
\hline
\end{tabular}

Table III

Evaluation of the KR-20 reliability coefficient for males and females in the algebra and calculusbased based courses.

\section{Conclusion}

We observe that the students in the algebra based course at Detroit Mercy perform at the same overall level as those in the sample of university students in the DIRECT study; however we do not see a significant gender gap. The males and females perform at the same level with the median score for males being 13 instead of 12. In the calculus based classes we note that the females score higher than the males in the algebra cohort-and similarly to those in the national sample-while the males score significantly higher. The male students in the calculus based course score almost one standard deviation higher than those in the national average. Furthermore, if the KR-20 coefficient is an effective measure of the reliability of the instrument, we find that DIRECT is less reliable for students in the algebra based course and is least reliable for females in that cohort. It may be the case that the biology students are less familiar with the "modeling" approach of instruction used in the laboratory and also on the assessment. Success on the DIRECT examination does rely on a student's ability to develop a mental model of certain physical concepts-current, voltage, resistance, equivalent resistance, etc. and then apply them to new situations. This type of modeling is typically not part of the curriculum in the life sciences and we wonder if it is responsible for the large differences in the variance of the student responses.

\section{References}

1 A. Arons, Teaching Introductory Physics, John Wiley \& Sons, New York, 1997, chapter 7 in particular.

2 McDermott, L.C., et.al., Physics by Inquiry, John Wiley \& Sons, 1996.

${ }^{3}$ McDermott, L.C., Shaffer, P.S., and the Physics Education Group, Tutorials in Introductory Physics, Prentice Hall, 1998.

4 Evans, J., "Teaching electricity with batteries and bulbs," Phys. Teach. 16, 15 (1978); doi: 10.1119/1.2339794.

5 McDermott, L.C., and Shaffer, P.S. "Research as a guide for curriculum development: An example from introductory electricity. Part I: Investigation of student understanding,” Am. J. Phys. 60, 994-1003 (Nov. 1992); https://doi.org/10.1119/1.17003.

6 Shaffer, P.S. and McDermott, L.C., "Research as a guide for curriculum development: An example from introductory electricity. Part II: Design of instructional strategies,” Am. J. Phys. 60, 1003-1013 (Nov. 1992); https://doi.org/10.1119/1.16979. 
7 Ekey,R., Edwards, A., McCullough, R., Reitz, W., and Mitchell, B., "A Fan-tastic Alternative to Bulbs:Learning Circuits with Fans," Phys. Teach. 55, 13 (2017); doi: 10.1119/1.4972490.

8 L.C. McDermott, "Millikan Lecture 1990: What we teach and what is learned-Closing the gap." Am. J. Phys. 59, (4) 301 (April 1991); doi: 10.1119/1.16538.

${ }^{9}$ National Science Foundation, Division of Science Resources Statistics, Women, Minorities, and Persons with Disabilities in Science and Engineering: 2009, NSF 09-305, (Arlington, VA; January 2009). Available from http://www.nsf.gov/statistics/wmpd.

10 P. J. Mulvey and S. Nicholson, "Physics Bachelor's Degrees," AIP FocusOn Report (2012), available at https://www.aip.org/statistics/women/degrees.

11 R. Ivie and K. N. Ray., "Women in Physics and Astronomy," AIP Report No. R-430.02, College Park, MD, 2005 available at www.aip.org/statistics.

12 L. Kost-Smith, S. J. Pollock, and N. D. Finkelstein, "Characterizing the gender gap in introductory physics courses,” PRST Phys. Educ. Res. 5, 010101 (2009) and references therein.

13 McCullough, Laura (2004). Gender, Context, and Physics Assessment. Journal of International Women's Studies, 5(4), 20-30. Available at: http://vc.bridgew.edu/jiws/vol5/iss4/2.

14 L. Kost-Smith, S. J. Pollock, and N. D. Finkelstein, “Gender disparities in second-semester college physics: The incremental effects of a "smog of bias"," PRST Phys. Educ. Res. 6, 020112 (2009) and references therein.

15 Z. Hazari, R. H. Tai, and P. M. Sadler, "Gender differences in introductory university physics performance: The influence of high school physics preparation and affective factors," Sci. Educ. 91, 847 (2007) and references therein.

16 Rennie, L. and L. Parker (1998). Equitable measurement of achievement in physics: High school students' responses to assessment tasks in different formats and contexts. Journal of Women and Minorities in Science and Engineering 4(2): 113-127.

17 Hake, R.R. 1998. "Interactive-engagement vs traditional methods: A six-thousand-student survey of mechanics test data for introductory physics courses," Am. J. Phys. 66, 64 (1998); doi: http://dx.doi.org/10.1119/1.18809.

18 P. Laws, P. Rosborough, and F. Poodry, Women's responses to an activity-based introductory physics program, Am. J. Phys. 67, S32 (1999).

19 McCullough, L. \& C.H. Crouch (2002). Gender, Educational Reform, and Instructional Assessment, Part 1. Paper presented at the national meeting of the American Association of Physics Teachers. Philadelphia, PA. Available at http://physics.uwstout.edu/staff/mccullough/physicseduc.

20 Adrian Madsen, Sarah B. McKagan, and Eleanor C. Sayre, "Gender gap on concept inventories in physics: What is consistent, what is inconsistent, and what factors influence the gap?” PRST Phys. Educ. Res. 9, 020121 (2013).

21 J. R. Shapiro and A. M. Williams, The role of stereotype threats in undermining girls' and women's performance and interest in STEM fields, Sex Roles 66, 175 (2012).

22 Ibid.

23 Ibid

24 S. J. Pollock, Comparing student learning with multiple research-based conceptual surveys: CSEM and BEMA, AIP Conf. Proc. 1064, 171 (2008) [http://www.compadre.org/per/items/detail.cfm?ID=8109].

25 P.V. Engelhardt and R. Beichner, "Students' understanding of direct current resistive electrical circuits," Am. J. Phys. 72 (1) 98-115 (2004); doi: 10.1119/1.1614813.

26 R. Ross, E.P. Venugopal, G. Hillebrand, M. Murray, and M. Gonderinger, "Results of a Multi-Year Assessment of Inquiry-Based Second Semester General Physics Laboratory Activities, ” in Proceedings of the 2014 American Society for Engineering Education (ASEE) Annual Conference \& Exposition, Indianapolis, IN, (2014).

27 R. Ross and P. Venugopal, "Inquiry-based Activities in a Second Semester Physics Laboratory: Results of a Two-year Assessment," in Proceedings of the 2007 American Society for Engineering Education Annual Conference \& Exposition, Honolulu, HI, (2007).

28 Kuder-Richardson Formula 20. (2016, November 18). In Wikipedia, The Free Encyclopedia. Retrieved 15:29, January 28, 2017, from https://en.wikipedia.org/w/index.php?title=Kuder\%E2\%80\%93Richardson_Formula_20\&oldid=750139826. 